\title{
MENTAL PAINKILLERS AND REASONS FOR PAIN
}

\author{
HAGIT BENBAJI \\ Ben-Gurion University of the Neveg \\ Department of Philosophy \\ Beersheba \\ Israel \\ benbaji@bgu.ac.il
}

\begin{abstract}
Article info
CDD: 152.44

\section{Keywords:}

Reason

Normativity

Mental pain

Grief

Mental painkiller
\end{abstract}

Received: 05.08.2018; Accepted: 09.08.2018

DOI: http://dx.doi.org/10.1590/0100-6045.2018.V41N4.HB

\begin{abstract}
What does bodily pain have in common with mental pain? According to "evaluativism," both are representations of something bad. This paper puts forward three claims. First, that evaluativism vis-à-vis bodily pain is false for it renders it irrational to take painkillers. Second, that evaluativism vis-à-vis mental pain is true. Third, that this difference between bodily and mental pain stems from the fact that only the latter is normative, that is, based on reasons. The normative difference between bodily and mental pain implies that mental pains are not bad, while bodily pains are not representations.
\end{abstract}

Pain is unique among perceptual experiences. It is not merely something which cannot be experienced without being exist, but something which cannot exist without being 
wished not to exist. The negative affect of pain, its painfulness, makes it bad, that is, gives us a reason to seek painkillers to get rid of it. Kripke once imagined yellow killer objects that kill whoever looks at them, but this thoughtexperiment by no means implies that a yellow-experience can be intrinsically bad. The yellow-experience has a very bad consequence, namely, death; but it is not bad itself. While the idea of a relief from yellow-experiences, yellow-experiencekiller, as it were, hardly makes sense, life without painkillers is hard to imagine.

Recently it has been suggested that pain is painful in virtue of its being evaluative, or more precisely, "a perception of evil" (Korsgaard 1996: 155). Evaluativism is considered to be the best version of representationalism visà-vis bodily pain, the theory that it is in virtue of representing a bodily disturbance that pain has its phenomenal character. Evaluativism requires that pain not only represent a bodily disturbance, but represent it as bad. ${ }^{1}$ The evaluative component is required because unlike ordinary perceptual experiences, say visual or tactile experiences, pain necessarily moves us to act against it, e.g., by taking medicines or painkillers. Ironically, evaluativism has been criticized for making the perfectly rational act of taking painkillers seem as irrational as shooting the messenger (Korsgaard Hall 1989, Bain 2013, Jacobson 2013). The messenger objection argues that evaluativism cannot explain what it is that renders a representation of a bad bodily disorder bad in itself, thereby making it rational to take painkillers. The very idea of a bad representation, a representation that constitutes a reason to seek its elimination, is suspect.

1 On various versions of Evaluativism vis-à-vis pain, see Bain (2013, 2017), Byrne (2001), Byrne and Tye (2006), Dretske (1995), Tye (1995, 2006), Helm (2002).

Manuscrito - Rev. Int. Fil. Campinas, v. 41, n. 4, pp. 01-32, Oct-Dec. 2018. 
This paper puts forward three claims. First, that evaluativism vis-à-vis bodily pain indeed renders it irrational to take painkillers. Second, that evaluativism vis-à-vis mental pain is not refuted by the messenger objection. Third, that this difference between bodily and mental pain stems from the fact that only the latter is normative, that is, reasonresponsive.

To explain the main idea in a nutshell, since the loss of a loved one gives me reason to feel grief, grief is not bad in the normative sense, that is, grief does not give me reason for its elimination. Grief is painful, indeed, no less than bodily pain; but its painfulness is appropriate, that is, there is reason to feel it, not to get rid of it. By contrast, since bodily pain is not based on reasons, its painfulness is bad-it always gives us reason to take painkillers. Since the badness of bodily pain cannot be derived from its being a representation of a bad bodily disorder, evaluativism cannot be true of bodily pains.

I begin by presenting the motivation for evaluativism (sec. 1), the messenger objection to it (sec. 2), and the analogy between bodily and mental pain that purports to refute the messenger objection (sec. 3). In the main body of the paper, I introduce the notion of a painful representation in order to argue that the comparison between bodily and mental pain is a double-edged sword for evaluativism. Although the appeal to mental pain shows why the messenger objection fails to prove the impossibility of a painful representation, inasmuch as mental pains are precisely such representations, the normative difference between bodily and mental pain reinforces the claim that mental pains are not bad, while bodily pains are not representations (sec. 4-9). 


\section{THE MOTIVATION FOR EVALUATIVISM}

A visual experience represents an object, e.g., a ball, as having certain properties, e.g., as being round and red. But a visual experience, say, seeing a red ball, also has a specific phenomenology - there is "something it is like" for a subject to see a red ball. Representationalism is a revolt against the view that the phenomenology of visual experience has a qualitative component-qualia--that cannot be explained by the experience's content. Denying the existence of qualia, Representationalism argues that the experience of something's looking red is simply a matter of its representing an object as red.

The representationalist view takes the experience of pain to be a matter of a perceptual state's somatosensorily representing some part of the body as being thus-and-so; it can thus be either veridical or non-veridical. To have severe neck pain, say, is not to suffer an intense sensation, but rather to be in a perceptual state that somatosensorily represents a bodily disorder located in the neck. Just as a visual experience of a pink ice-cube informs us that there is a pink ice-cube over there, so too pain informs us, by dint of its representational content, that some part of our body is disordered. On this account, pains are not merely akin to perceptual states, they literally are perceptual states (Bain 2013: 72).

Yet it seems that the painfulness of pain is conspicuously missing from the representationalist account. Seeing a red ball does not-in itself-motivate us to do anything (by contrast, wanting to play football, and liking the color red, I might be inclined to choose a red ball over a yellow one). But pain is not 'inert' in this way. Pain does not leave us "cold": it drives us, simply by virtue of how it feels, to fight it (Korsgaard 1996), e.g., to go to a doctor, take medicine, undergo surgery, etc. The phenomenal aspect of pain, being painful, is inseparable from pain's motivational force. Moreover, the 
assertion that pain motivates us to act is not just a descriptive claim about how we respond to pain, but also justifies our response, viz., our efforts to eliminate the pain by, e.g., taking medicine. Pain provides us with both motivating and normative reasons for actions.

Were pain simply a perceptual experience, it would lack motivational power. Bain explains the motivational failure of a purely perceptual experience as an example of Hume's argument for the motivational inertness of beliefs about that which is a mere "matter of fact." Any representation of a matter of fact is motivationally inert, and so if pain were a representation of a mere matter of fact (a bodily disorder), it would be motivationally inert. Even representationalists about pain acknowledge that "a theory which says that pains merely represent tissue damage at some location in one's body would seem to leave out the painfulness of pain" (Cutter and Tye 2011: 92).

Although factual representations do not motivate us to act, evaluative representations do. ${ }^{2}$ In order to explain the motivational power of pain, evaluativism adds representation of values to representation of mere facts.

For an experience to be pain is for it to somatosensorily represent a bodily part as (1) having a disturbance of a certain sort, e.g., some disorder or damage, and (2) that experience also represents the bodily disturbance as bad for the subject, in the bodily sense (Bain 2013: 82).

2 This claim is controversial: belief-desire theorists do not accept it. In fact, Bain restricts the claim that evaluative representations motivate us to act to perceptual experiences (2013: 84). 
What is it for a disturbance to be bad in the bodily sense? Bain replies that this badness is "simply its being apt to harm the subject's body, in the sense of being apt to impede its proper functioning" (Bain ibid., ibid.). ${ }^{3}$ But the crucial claim is that the motivational power of pain is derived from its representing a bodily disturbance as being bad. In enriching the content of pain so that it includes not merely the representation of a physiological disturbance, but also a representation of that disturbance as bad, evaluativism promises to explain what the purely perceptual model cannot - the motivational power of pain.

\section{THE OBJECTION FROM SHOOTING THE MESSENGER}

Pain provides us with reasons to take two sorts of action: actions to ameliorate the bodily disorder, such as going to the doctor, undergoing surgery etc., and actions to quell the pain, regardless of the bodily disorder, such as taking painkillers. We typically attempt to eliminate pain by seeing to it that illnesses are cured, wounds are healed, or bodily organs are moved out of danger (withdrawing one's hand from a hot stovetop); alongside all that, we also take painkillers.

Korsgaard argues that evaluativism might seem to exclude the rationality of the second mode of acting to end our pain. The difficulty for evaluativism is particularly conspicuous when one suffers pain without bodily disorder, or when the bodily disorder is beyond curing:

${ }^{3}$ Bain qualifies this claim by the assertion that a disturbance is bad only if the subject cares about his proper functioning (2014). See also Helm 2002. 
In some cases, pain is a misperception of a reason: there is no underlying malfunction or identity-threatening condition that it signals. In others, there is one, but there is nothing we can do about it: the person, or the animal, is beyond help or cure. Yet in these cases, we are still concerned to alleviate the pain. Someone is dying of an incurable disease; or an animal must be killed--we want to make things as painless as possible for them. If a pain is not a perception of a reason, or if we can do nothing about the reason that it does perceive, is there then no reason to alleviate it? (1996: 153).

In other words, in cases where we know that pain falsely represents a bodily part as disordered, or where we can do nothing about it, doesn't evaluativism imply the absurdity that we have no reason to object to it? ("is there then no reason to alleviate it?"). Or does it show, as Hall claims, that each time we take a pain killer, we behave "like the ruler who slew the messenger who brought the bad news" (1989: 647).

In order to develop this argument, Jacobson suggests that we examine the way belief, the paradigmatic representational attitude, provides us with reasons. A belief is a 'conduit' for the fact it represents (Stamp 1987: 343). "The reason-giving force of a belief is rooted in the fact about which the belief informs the subject" (Jacobson, ibid. 517). Just as belief can represent something bad without being bad itself, so too the mere fact that an experience represents something as bad cannot make the experience itself bad. There is nothing bad in "being in a state which merely represents that another state is bad" (Jacobson, ibid). The argument is not merely extensional (a belief is not itself bad); rather, it claims that a belief is not bad because its normative force is directed outwards, to the properties it represents. Similarly, Bain asks, "what is so bad about being somatosensorily informed that your foot is in a bad state? Why shoot the messenger if you know the message is false? Indeed, returning to the veridical 
case, why shoot the messenger even if you know the message is true?" (2013: 86).

The messenger objection is not another version of the Humean argument against the motivational power of a belief. While Hume challenges the possibility of a representational state that is inherently motivational (how can a mere representational state motivate us to act?), the messenger objection challenges the possibility of a representational state that is inherently bad, i.e., a representational state that inherently justifies us to eliminate it (how can a mere representational state motivate us to act against it?). Jacobson and Bain claim that evaluativism cannot explain what it is that renders a representation of a bodily disorder bad in itself, thereby providing us with reasons to take action against it.

Opponents of evaluativism conclude that a representation cannot be painful simply by virtue of its content; if it were, it would constitute a reason for its own elimination. Proponents of evaluativism give up the intuition that pain is intrinsically bad, that is, that it provides us with reasons (justifying and motivating, I shall drop this qualification henceforth) to eliminate it simply by virtue of how it feels. Pain constitutes a reason for its own elimination not in virtue of its phenomenology, but in virtue of something else. Some views appeal to a standing desire against the painfulness of pain to explain the badness of it, whereas the evaluative content explains the bodily-directed motivation and normativity (Cutter and Tye, 2014). Other views appeal to pain's bad consequences (Cutter and Tye 2014), e.g., it disturbs and distracts us. It is because pain has such bad consequences that we want to be rid of it. If pain somehow lacked these adverse consequences, we would not be motivated to eliminate it. As Korsgaard optimistically puts it, "pain wouldn't hurt if you could just relax and enjoy it" (1996: 147). 
The challenge for evaluativism regarding bodily pain is to explain how it can preserve the intuition that pain is intrinsically bad, that is, the intuition that pain justifies taking painkillers solely in virtue of the way it feels, not merely because of its bad consequences or because we do not like it.

As far as I know, Bain's appeal to emotions, and specifically, negative emotions, is the only attempt to address the challenge of explaining the claim that pain is intrinsically bad, bad in virtue of how it feels.

\section{THE PHYSICAL PAIN-MENTAL PAIN ANALOGY: THE POSSIBILITY OF BAD REPRESENTATION}

On the face of it, a powerful counterexample to the conclusion of the messenger objection suggests itself:

Grief is a state in which a death strikes you as bad — indeed awful—for you; and we recognise that something's striking you that way is itself bad for you. Again, grief's effects (e.g. exhaustion) can be bad, to be sure; but grief is also bad intrinsically-it is itself a kind of suffering-and this is so, I am claiming, because grief is a state in which a death strikes you as bad for you (Bain 2013: 87).

It appears that because grief represents the death of a loved one, grief itself is painful, "a kind of suffering", not merely its consequences.

The strength of the analogy to mental pains comes from how natural it is to regard their content as the reason for how they feel. As Nussbaum describes the moment she was informed of her mother's death, "this news felt like a nail suddenly driven into my stomach" (Nussbaum 2007: 19). While the representational nature of bodily pain is not 
reflected in ordinary experience, and indeed, it is far from clear what it even means to be "somatosensorily informed that one's foot is in a bad state" (Bain 2013: 82), we know perfectly well what it is to receive grievous news. The claim that emotions such as hate, anger, sympathy, fear, and grief-that is, mental pains--are painful in virtue of their being about painful situations in the world is commonplace:

Affectivity as introspection reveals it to us is in fact already a constituted affectivity; it is consciousness of the world. All hate is hate of someone; all anger is apprehension of someone as hateful or unjust or faulty; to have sympathy for someone is to 'find him sympathetic', etc. (Sartre 1992: 435)

Sympathy is ... the pained awareness of ... distress as something to be relieved (Nagel 1970: 80 n.1).

To feel fear is to be pained by danger ... in the sense that the danger impresses itself on one, grabbing one's attention and motivating one to act; the emotional response, the feeling of this danger, just is the pain (Helm, 2002: 19).

Let me characterize the notion of affective, or more specifically, painful representation, as follows:

a painful representation $=$ a representation that is painful simply by virtue of its content

Given the wildly held view that mental pain is, indeed, painful in virtue of representing a bad situation in the world, Bain draws an analogy between mental pain and bodily pain to counter the conclusion of the messenger objection, that 
is, to show that there are intrinsically bad representations. Representational attitudes like grief or anger, are, unlike mere beliefs, intrinsically a form of suffering. Thus, he concludes that negative emotions constitute, by dint of being negative, that is, painful, a reason to take action against them.

To strengthen the plausibility of a bad representational state, Bain compares phantom pain, i.e., suffering pains in one's leg while knowing that there is no leg, to recalcitrant fear, e.g., fearing the spider while believing it is harmless, or suffering pains in one's leg while knowing that there is no leg (2013: 87). It is clear that in fearing the spider, one has a (false) representation of danger, a representation that one has a reason to eliminate. The analogy with fear and grief seems to refute the messenger objection, in that fear and grief are not merely conduits reporting a bad state, but rather exemplifiers of an intrinsically 'bad' representation. Appealing to the comparison to mental pain, Bain appears to address the challenge successfully, upholding evaluativism without relinquishing the intuition that pain constitutes a reason for its elimination simply by virtue of how it feels.

\section{THE MESSENGER AGAIN: THE IMPOSSIBILITY OF BAD REPRESENTATION}

The messenger objection, as stated, fails, for it relies on the manner in which evaluative beliefs provide us with reasons. Typically, belief is 'cold', that is, neither bad nor painful in itself, and thus can provide us with reason for an action without affectivity. ${ }^{4}$ Bain responds that other

\footnotetext{
${ }^{4}$ The assumption that evaluative beliefs are 'cold' or affect-less is also questionable. As Little argues, evaluative beliefs are "certain ways of seeing or of conceiving the world, ... that one cannot have without reacting effectively in a certain way" (Little 1997: 71).
} 
representations, namely, negative emotions, are not 'cold,' and they are not cold because of what they represent. I accept Bain's claim that negative emotions are painful representation, that is, painful in virtue of what they represent. To do justice to the possibility of affective representation, the messenger objection needs to be reconstructed without relying on the belief model.

An alternative construal of the messenger objection begins with the question of what kind of reasons for action can a representational attitude provide us with. Obviously, reasons that pertain to this content in particular, to the normative properties that the attitude represents. If I believe that going to England is bad (or good), this attitude gives me reason to resist (or support) going to England, not reason to resist (or support) going to France. Similarly, if my pain is a representation of my broken arm as bad, this gives me a reason to tend to my arm, not to my computer. If my pain does not figure in its content, that is, if its content is not selfreferential, then it-my pain-does not constitute a reason to act regarding the pain. Of course, insofar as tending to my arm amounts to ending my pain, I have (derivative) reason to stop my pain. But I do not have any reason to take painkillers simply because my arm is broken. Let me call this simple observation the content-principle. The content principle leads to a reductio ad absurdum of evaluativism vis-àvis bodily pain, without relying on an explanation of the way 'cold' belief provides reasons:

1. The painfulness of pain gives us reason to get rid of it by virtue of how it feels (badness).

2. A reason to get rid of the pain cannot be derived from its content (from the content principle).

3. The painfulness of pain cannot be derived from its content. 
4. Pain is not a painful-representation.

Notice that this argument is in one way broader and in another way narrower than the original messenger-objection. It is broader, because the content principle claims that the fact that $p$ is bad constitutes reasons against $p$, that's all. It does not constitute reasons against representing $p$, desiring that $p$ will cease, hoping that $p$ will disappear, commanding that $p$ will go away, etc. In this form, the argument is effective also against theories that identify pain with a desire or imperative that is directed towards the bodily damage, rather than the pain experiences. As long as pain is not included in the content of the desire or the imperative, the attitude may justify ceasing the bodily disorder, but not taking painkillers to get rid of it. The content principle proves that we cannot derive the badness of a painful representation from its content, no matter what kind of representation it is (belief, emotion, desire, imperative, etc.).

Bain accepts that the badness of your bodily condition only justifies taking care of your bodily condition, not ending your pain experience; so why is your pain experience bad? Bain's idea is that the badness of your pain experience is derived from the badness of your bodily condition via the notion of painfulness: "something's striking you as bad is painful itself and thus bad for you". Thus, he argues that from the fact that

\section{a. Grief is "painful in itself"}

follows the conclusion that

b. Grief is "bad in itself," that is, gives us reason for its elimination.

In fact, Bain does not present this as a form of inference; he seems to take the claim that grief is a form of suffering to 
mean that grief is normatively bad, that is, constituting a reason for its elimination. But as the alternative reconstruction of the messenger objection shows, the idea of bad representation is absurd.

I argue that the inference from $a$ to $b$ is invalid. The notion of painful representation does not imply bad representation. My argument, in contrast to the original messenger objection, allows for the existence of painful representation. The premises of my argument outline what reasons a representational attitude can provide us with. The conclusion of the messenger objection, as I reconstructed it, is simply that it is the badness of a representational attitude, rather than its painfulness, that cannot be derived from its content. In this sense, the argument from the content principle is narrower than the original messenger-objection.

The possibility of painful-albeit-not-bad representation might seem like an oxymoron: no one wants to be in pain, so everyone wants to get rid of pain. Thus pain, be it physical or mental, is intrinsically bad. However, as I shall now show, the fact that no one wants to be in grief does not imply that grief is bad. Negative emotions are painful representations, but they are not intrinsically bad.

\section{A RESPONSIVE MESSENGER: THE POSSIBILITY OF PAINFUL (BUT NOT BAD) REPRESENTATION}

A remarkable fact about grief is that although it is very painful, it does not, simply by virtue of the way it feels, constitute a reason to seek its elimination. As Korsgaard remarks, "No one, I suppose, would choose not to experience grief at the death of a loved one at all, although we are rightly afraid of finding it unbearable. We may object to a world in which our loved ones are taken away, but if they are taken away, we do not want to fail to experience the fact, to register it as an evil" (1996: 154). 
While it is absurd to deny that we have reason to take painkillers to subdue bodily pain, the disanalogy between bodily and mental pains is that it is by no means absurd to deny that we have reason to subdue mental pain. It is not true that

Grief, simply by virtue of the way it feels, justifies our taking painkillers.

In the face of loss, we want to feel grief; we believe that we have no reason to take the pill. Why? Because grief seems to be appropriate, the right way to respond. The rationale for the disanalogy is that mental pain, but not bodily pain, is based on reasons. The normativity of mental pain renders it diametrically opposed to bodily pain, in so far as we have good reason to feel mental pain and to not seek its elimination.

To say that mental pains are, like emotions in general, based on reasons, is to say that they are 'sensitive to judgments' (Scanlon 1998: 20), in the sense of being open to criticism. We do not expect our bodily pain to disappear upon our judging that there is no bodily disorder, but we expect our fear to be dispelled upon judging that we are not in danger. We cannot habituate ourselves to not feel bodily pain, as we can habituate ourselves not to get carried away by jealousy each time we see our former spouse with a new lover. We do not criticize ourselves for being in pain, but are disappointed with ourselves when we cannot feel happiness, or worse, feel sad for the success of a friend.

Thus, although the focus of this paper is on grief, less dramatic examples of mental pains (e.g., fear, sadness or anger) are no less decisive: one should feel sad, or even heartbroken, when close relationships come to an end. Not to feel anything upon the dissolution of a close friendship would be insensitive. Similarly, though it is highly unpleasant to feel shame or regret, it is appropriate to feel regret, and be 
ashamed of, one's hurtful conduct. And to say that it is appropriate to feel sadness, shame, or regret is to say that sadness, shame and regret do not, simply by virtue of the way they feel, constitute a reason for their elimination.

Back to the example of grief, my central claim is that since grief is sensitive to, or justified by, the judgment that a loved one has passed away, the content of this judgment-a loved one has passed away-exhausts the reason giving force of grief. Even if a pill against grief were invented, we would not choose to take it. Grief is certainly painful, and as would be expected, entails the wish that one did not have to suffer so. But to wish that one was not undergoing the painful experience is to wish that the death had not occurred, not to wish that one could forego responding to the death. The wish not to feel grief is wholly derivative from the wish that the loved one would come back. Not only do we not want to eliminate (appropriate) grief, but when we cannot feel grief in the face of loss we wish to feel it and make an effort to experience the painful emotion; we endeavor to respond to the loss appropriately. It is as if, were there a grief-generating pill, we would choose to take it.

This does not mean that it is appropriate to feel grief for as long as possible after one's beloved die. It is inappropriate to be grieving for one's entire life. Emotions in general are appropriate for a certain duration; they come with "an expiration date" (it is not appropriate to be angry of a childhood friend for years). How long one should grieve (ten years seems too long, two months seems too little) is, in part, a personal matter. ${ }^{5}$ But the sheer commonsense observation that we would like our loved ones to go on living happily at

5 According to some empirical research, many stop grieving after two months. Moller argues that this is objectionable: "we are not only surprised but shocked and dismayed by these results" (2007: 305). 
some point does not undermine the claim that an appropriate grief does not give us reason to eliminate it. It only means that the loss does not deserve grieving for the rest of one's life.

It might be suggested that the practice of consolation is an attempt to eliminate someone else's mental pain. If the painfulness of grief is reason for others to seek to lessen my grief, why is it not a reason for me? This objection expresses a misunderstanding of the nature of consolation. Consolation does not seek to provide someone with reasons not to feel sorrow altogether:

When one's friend is grieving, one ought to be there to give comfort and support, and doing so may help make grief bearable, or at least less bad. In many cases such comfort reduces the amount of suffering that occurs. But to require this sort of amelioration is not to require the elimination of the suffering. Indeed, even if this were within our power, if, for instance, I had a pill that I could give my grieving friend that would wipe out her grief, it would, it seems to me, quite likely be wrong for me to offer it (Jollimore 2004: 342).

The goal of consolation isn't to eliminate grief; at best, consolation makes grief more bearable. Once again, this is consistent with our attempt to relieve the pain of grieving people by trying to take their mind off of their grief for a bit -- taking them to a movie, say. But this is not a way to eliminate grief altogether, only a way to relive the pain temporarily.

That it is inappropriate to take a pill to eliminate grief sheds light on why, with regard to mental pain, the rhetoric of 'merely a messenger' is misleading. Mental pain is not an uninvolved, neutral messenger. Rather it is a responsive or 
sensitive messenger; it delivers the message by responding to it appropriately, namely, painfully. Remaining unmoved in face of loss is inappropriate. Bain's reply to the messenger objection seems to be trapped by his own metaphor. He seems to grant that if the message makes the messenger itself unpleasant or painful, as is the case with grief, then it is rational to kill the messenger. But grief's painfulness makes it an appropriate response to the loss, and thus does not provide us with a reason to seek its elimination. On the contrary, it gives us reason to embrace-or at least submit to- - the feeling of grief. ${ }^{6}$ Indeed, it is better to kill a mere messenger, who remains cold by the bad news, than a responsive messenger, who brings them with great emphaty.

By contrast, bodily pain is not based on reasons, that is, it is not appropriate, apt or suitable to feel it. Helm (2001) objects that we also "can and do assess bodily pleasures and pains for warrant, depending on whether their objects (what is going on in one's body) can intelligibly seem to have the relevant import. Thus, we criticize children for feeling pain too readily ("That doesn't hurt!'). But we criticize children not for feeling pain too readily, but for behaving as if they suffer pain too readily. We assume that they do not really feel pains, or not that much, and we criticize them for panicking, screaming, etc. When we suspect that they do feel pains, we do not criticize them.

Let me emphasize that I rely on our intuitions in assuming that bodily pain is not based on reasons. Perhaps the evaluativist ought to say that the pain of a phantom limb is inappropriate. But we would not criticize this pain in the

\footnotetext{
${ }^{6}$ Notice that the case of grief undermines the desire account as well: the griever has a frustrated desire that her beloved will come back, but she does not want to get rid of her desire. The longing to the beloved, the wish that he will be with her, is not bad though it is certainly painful.
} 
way we criticize feeling anger about a friend who did nothing wrong. Relatedly, though in some cases it is better not to take painkillers in order to guard well, this does not show that the pain is appropriate-only that suffering it has good consequences.

Since bodily pain is not based on reasons, its painfulness always implies badness, i.e., always gives us reason to take painkillers. Such reasons cannot be derived from the representation of a bodily disorder as bad, and hence, evaluativism cannot be true of bodily pain: a bad representation is, indeed, impossible. But negative emotions are reason-responsive, we have reasons to feel them rather than getting rid of them. Hence, evaluativism can be true of mental pain.

To summarize, the insight of the messenger argument is that a representation of something bad is not bad in itself. The mistaken conclusion of the messenger argument is that such a representation is not painful. Thus, from the fact that

a. Grief is "painful in itself"

it does not follow that

b. Grief is "bad in itself," that is, provides us with a reason to seek its elimination.

From the fact that there is nothing bad in "being in a state which merely represents that another state is bad" it does not follow that being in this state is not painful. Grief is a painful awareness of a loss, not a cold or neutral representation. Indeed, grief is no less painful than physical pains. But mental and physical pains are painful in different ways. In the case of physical pain the way it feels constitutes its being bad, while in the case of mental pain the way it feelspainful-is appropriate. Let me emphasize that I mean badness in the normative sense, that is, in the sense of 
providing us reasons to get rid of it. Of course being in a painful state is bad in another sense-in the sense that a bad thing happens to us. The painfulness of mental pain, but not of bodily pain, is a response to a bad situation in the world. Since intentional painfulness is a sensitive or appropriate response to its object, it cannot be intrinsically bad.

\section{IS THE IDEA OF A PAINFUL REPRESENTATION COHERENT?}

The possibility of a painful representation might be considered no less mysterious than that of a bad representation. A proponent of the messenger objection may claim that acknowledging painful representations involves the same fallacy that is grounded in the incoherent idea of a bad representation. Granted-a representation does not become bad simply by representing a bad state of affairs. But in the same way, one may wonder, a representation does not become painful simply by representing some painful state of affairs: how can a state's representing another state as bad or painful be painful in itself?

The rhetorical question loses its force when it comes to grief. Indeed, the point of Bain's appeal to emotions in the first place is that we are pained by realizing that we have lost someone close. More substantively, there is no mystery in the idea of a painful representation, because the same aspect of grief that explains why it is not bad, also explains why it is painful, i.e., its appropriateness. To say that grief is appropriate is to say that it fits the property it represents (e.g., a loss): it is painful.

One may still be puzzled by the idea of responsive representation, a representation that somehow replicates what it represents. As an experience of redness is not itself red, so too, an experience of painfulness (e.g., a loss) is not itself painful, or so goes the objection. I cannot do justice to 
the notion of responsive representation, beyond pointing to the sensitivity conception of values, the view that values merit specific sentiments (Wiggins 1987, McDowell 1986: 159). On this view, without experiencing emotional responses to evaluative facts, we would be unable to perceive or conceive of values. To represent a state of affairs as bad (or better, as bad in a specific manner-wrong, frightening, humiliating, etc.) is to conceive of it as the sort of thing that deserves a painful response (e.g., sorrow, fear, shame). There is nothing mysterious about the notion of painful representation, it is simply the appropriate response to badness. The point is not that the representation replicates that which it represents, but that there is a proper fit between the represented property (e.g., a loss) and its representation (grief): values and sentiments seem to be 'made for' each other (Wiggins 1976: 206, McDowell ibid. ibid.). ${ }^{7}$

One might argue that John can come to believe that his beloved mother is dead, and feel nothing. If the realization that his dear mother died can leave John cold, it is not clear in what sense such a realization fully explains grief. ${ }^{8}$ Perhaps the correct response to this objection is to deny that the very content that calls for grief can leave one cold. Nussbaum claims that "the knowledge of the evaluative significance of the death has not yet sunk in. ... What he is not fully acknowledging or taking in is the thought, "A person whom I truly love, who is central to my life, is dead." For to recognize this is to be deeply disturbed" (2001: 41). The

${ }^{7}$ I cannot discuss sensitivity theories further here, but let me just emphasizes that it implies that we could not have evaluative beliefs without the capacity to respond sensitively, that is, emotionally. This dependency provides us another reason to reconstruct the messenger objection without relying on the way beliefs provide us with reasons.

${ }^{8}$ Thanks to Michael Brady for raising this objection.

Manuscrito - Rev. Int. Fil. Campinas, v. 41, n. 4, pp. 01-32, Oct-Dec. 2018. 
evaluative fact, properly stated, cannot leave one cold. When one fully realizes the significance of the loss, one grieves.

\section{IS THE IDEA OF PAINFUL-BUT-NOT-BAD COHERENT? A 'VACILlation RESPONSE'}

An advocate of the analogy between bodily and mental pain might agree that we usually do not choose to remain emotionless in the face of loss, but deny that this choice shows that grief's painfulness does not give us reason to desire its elimination. The fact that we have a reason to grieve doesn't imply that there's no reason to get rid of grief. Although we usually succeed in ignoring this reason, that grief generates a reason for alleviation is inherent to its painfulness. This 'vacillation' response to negative emotions, as we might call it, represents us as forever torn between two contradictory reasons - to feel pain in light of the bad situations we find ourselves in, and not to feel pain in light of their painfulness.

Yet characterization of our response as vacillation between feeling grief over the terrible loss, and seeking to relieve the grief due to its painfulness, distorts our reaction to such losses. Think of how inappropriate it would be to respond to the news about the loss as follows: "Indeed I loved him dearly, and now he is gone, but I just don't want to feel the pain-it hurts too much." A desire not to feel anything - to be emotionally 'numb,' as it were-in face of loss reflects a belittlement of one's friendship with the deceased, failure to appreciate the meaning of friendship, or insincerity as to one's affection for the deceased, and in this sense, it is reprehensible. Were it the case that grief, simply by virtue of the way it feels, gave us reason to seek its elimination, then refusing to feel grief would not be deemed reprehensible.

A proponent of the 'vacillation' response may grant that we generally prefer to feel the appropriate emotion, and further, that we condemn the other response. Though the 
painfulness of grief does not usually 'win out' over the appropriateness of grief, and in this sense, we do not really vacillate between grief's appropriateness and its painfulness (let alone "torn between two contradictory reasons"), the painfulness of grief is nonetheless a consideration in favor of taking the painkiller. It might be outweighed or defeated by the appropriateness of grief, just as prudential reasons are arguably generally defeated and even rendered reprehensible by moral reasons, or a food's nutritiousness sometimes defeats its deliciousness. Nevertheless, grief's painfulness does constitute a reason to take a painkiller, as prudential considerations, even when outweighed, are bona fide reasons.

However, the comparison with two aspects of an action is deeply misleading. A food can give rise to contradictory reasons in virtue of two different aspects, its deliciousness and its nutritiousness. But it is the same aspect of grief that, allegedly, calls for contradictory reasons, namely, its painfulness. It is the painfulness of grief that makes it the appropriate response to the loss, and it is the painfulness of grief that allegedly, gives us a reason to eliminate it. But it is incoherent to suppose that one and the same aspect provides us with contradictory reasons.

The proponent of the 'vacillation' response might invoke the distinction between state-given and object-given reasons to deny that one aspect of grief is the source of contradictory reasons. Object-given reasons for an attitude (e.g., epistemic reasons for beliefs) pertain to its content, whereas state-given reasons (e.g., pragmatic reasons for beliefs) are facts about the psychological states associated with our having that attitude (e.g., our having been offered a million dollar prize to believe that a world war will break out tomorrow). 9

9 Parfit 2001, Piller 2001, Hieronymi 2005. Various objections to 
Reasons to feel grief are object-given reasons that make grief appropriate, while reasons to take the pill are state-given reasons that justify our seeking the elimination of grief. The content of grief is the source of its object-given reason, while the state of having grief is the source of the state-given reason. As pragmatic reasons do not undermine the justification of epistemic reasons for beliefs, so too, taking the painfulness of grief to constitute (state-giving) reason for its elimination does not undermine its appropriateness. Rather, its appropriateness is an overwhelming reason to feel it, much stronger than the (state-given) reason to eliminate it provided by its painfulness (D’Arms, J. \& Jacobson, 2000).

However, grief's appropriateness and painfulness are not distinct aspects of grief that can be logically separated, as the moral and the prudential aspects of an action, or the delicious and nutritious aspects of a food can be separated. We can assess a food's nutritiousness regardless of how tasty it is, and vice versa, just as we can consider an action's morality regardless of the benefit it confers, and vice versa. But we cannot think of grief's appropriateness without regard to its painfulness. To consider its appropriateness is to think of how painful it is to lose a dear friend. In reflecting on the appropriateness of grieving, we cannot set aside its painfulness, 'bracket it out' as it were, for the painfulness of grief is precisely what makes it an appropriate response to the loss of someone dear. When one grieves appropriately, one has already attended to the painfulness of one's grief; there is no aspect or consideration that is suppressed or outweighed.

Acknowledging that painfulness is not even a consideration to be weighed against its appropriateness, it might be tempting to borrow McDowell's famous idea

this formulation of the distinction have been raised; for the most recent, see Schroeder 2012 and Hieronymi 2012. 
regarding the requirements of virtue, and claim that the painfulness of grief is silenced in the face of loss. On this suggestion, the painfulness of grief may not constitute a reason at all when one faces a loss of a close friend, just as losing a leg is no reason at all to run away in a crucial battle. Admittedly, McDowell's demand that for the courageous, "here and now the risk to life and limb is not seen as any reason for removing himself" (1979: 56) is controversial, to say the least. However, silencing is much less controversial when applied to situations that require grief. Upon being informed of a loss of a close friend, all I can think of is the loss of my friend, not my pain.

The metaphor of silencing, however, is also misleading and for the same reason, namely, that we cannot abstract grief's painfulness from its appropriateness. To think of the loss of my friend is to think of how painful it is to lose him. A consideration can be silenced when we can abstract its normative power from the situation at stake (a risk to life is a reason to run away when there is nothing important at stake). But the painfulness of grief cannot be thus abstracted; it cannot be silenced, for it is precisely this aspect of grief that makes it appropriate, that is, the fitting response to the loss.

\section{THE ETHICS OF EMOTIONS}

One might argue that the painfulness of appropriate grief sometimes gives us reason to alleviate, reduce, or eliminate it altogether. When we are desperate for a full night's sleep, unable to care for our children, wish to get important work done, or, to give a more extreme example, are recovering from a heart-attack--in such cases grief, though appropriate, seems to constitute a reason to seek its elimination.

In these cases, grief indeed constitutes reason to seek its elimination, but not simply by virtue of what it feels like. 
Rather, it does so by virtue of its adverse consequences. Thus, it is not the case that grief is a source of a state-given reason to seek its elimination, simply by virtue of how it feels.

The phenomenology of negative emotions makes room for what we can call 'the ethics of grief.' I can ask myself whether to continue grieving, as appropriate, or take a pill, in light of the adverse consequences my grief may have (neglecting my children). Given the painfulness of negative emotions, the ethics of emotions is, indeed, a live question. ${ }^{10}$ While the ethics of belief often lends itself to discussion of philosophical fantasies about millionaires, questions about the ethics of emotions generally arise because they are painful. My contention is that grief's painfulness is not itself a state-given reason to seek to eliminate our grief, but rather grief constitutes a state-given reason for its elimination in virtue of its consequences.

One may claim that it just so happens that in the case of grief we care a lot about having appropriate feelings (perhaps because of the value friendship holds for us), and do not take grief to provide us with a state-given reason to seek its elimination unless it has adverse consequences. Grief is thus misleading. Consider anger instead. Anger is a constant source of frustration that poisons many lives. The painfulness of anger, in contrast with that of grief, seems to always provide a reason to wish we didn't feel it, a reason to seek its elimination. This reason is a constant motivation that often prevails, and justifiably so. In contrast to grief, even absent any adverse consequences the painfulness of anger is a justified (state-given) reason for wishing we didn't feel it. Indeed, anger, and perhaps other negative backward-looking emotions, e.g., regret and disappointment, are never appropriate. As Spinoza argues, "repentance is not a virtue, i.e.

${ }^{10}$ I develop the idea of the ethics of emotions in a different paper (in progress). 
it does not arise from reason. Rather, he who repents what he did is twice miserable, i.e. impotent" (pt. IV, prop. 54), and Nietzsche contends that it is "double stupidity". Bittner extends the claim to grief: one can truly love one's friend, fully understand that the friend is dead, and go on living happily ever after (1992: 264).

I find this account dubious. Emotions are not, as Helm (2002) argues, separate episodes in one's life, but part of a holistic web that is constituted by, among other things, caring about people, projects, etc. Caring about a friend involves vulnerability to various emotions in various circumstances (e.g., happiness when the friend achieves a longtime goal, sadness upon her demise). Positive and negative emotions are "two sides of the same coin, constitutively connected to each other as different aspects of a single underlying syndrome or stance" (Wallace 2013: 31).

I cannot defend the holistic nature of emotions here, nor need I do so. Let us assume that regret and anger always provide us with reason to seek their elimination. This means that there is something in the state of anger, over and above its specific content, that is bad in itself, warranting its elimination. If anger in and of itself, simply by virtue of what it feels like, warrants its elimination, then anger is not, or is not solely, a representation. If anger gives us reason to seek its elimination simply by virtue of what it feels like, anger is (also) directed inward, to its painfulness. More generally, if a state provides us with a reason, simply by virtue of what it feels like, to seek its elimination, there must be more to it than its being a representation of some bad occurrence in the body (or the world). Since grief's normative force is, as I argued, exhausted by its content, grief is purely representational. 


\section{THE PAINFULNESS OF GRIEF}

But if grief does not, simply by virtue of the way it feels, supply us with a reason to seek its elimination, that is, if grief is not bad, in what sense is it painful? Evaluativism's proponents and opponents alike identify painfulness with badness, namely, with constituting a reason to seek its elimination. They assume that if we do not want to rid ourselves of the state we are in (at least prima facie), surely that means that it is not painful. I deny the entailment. From the fact that grief does not, simply by virtue of the way it feels, give us reason to seek its elimination, it does not follow that grief is not painful. It follows that grief is not (normatively) bad. But then, the question is raised again: in what sense is grief painful?

I've already argued that grief, like other painful representations, does imply a wish not to be in this state (sec. 5). Accordingly, painfulness implies either that we want to eliminate the state itself (as in the case of bodily pain) or that we wish that the bad situation had never occurred (as in the case of mental pain). When grieving, we certainly do not want to be in this state, but it is the second disjunct that is implied: we wish that the loved one was still with us. Thus, the core idea of painfulness implies a wish not to be in such a state. That is why mental and bodily pains are all painful.

Sometimes, the wish not to be in this (painful) state may be a source of motivation (rather than reason or justification) to take the pill, and seek the elimination of the pain. Going through a painful breakup of a long-term relationship, the desire not to be in this state may motivate me to take the pill in order to get rid of the painful memories, the frustrating anger, etc. As I previously argued, this motivation does not justify me in taking the pill (for my pain is an appropriate response to the painful ending of a significant relationship). Although the wish not to be in the painful state is derived 
from the wish to continue the relationship, and thus appropriate, it can tempt me to take a pill to end the pain.

Furthermore, this wish is translated into the language of reasons (not merely motivations). When the emotion is unjustified or inappropriate (excessive, misplaced, insincere), its painfulness can warrant our seeking to eliminate it. Alternatively, where the negative emotion is appropriate, but has some bad consequences, the painfulness is a source of state-given reasons to seek its elimination. The fact that the ethics of grief, unlike the ethics of belief, raises live questions indeed attests that grief is painful.

Though mental pains are no less painful than bodily pains, they are painful in different ways. We have no reason to rid ourselves of mental pains; on the contrary, we have reason to feel them. By contrast, there are no such reasons in the case of bodily pains, which is why it is rational to take painkillers to eliminate them. ${ }^{11}$

\section{REFERENCES}

BAIN, D. "What Makes Pains Unpleasant?", Philosophical Studies, 166: 69-89, 2013.

"Pains That Don't Hurt." Forthcoming in Australasian Journal of Philosophy, Vol. 92, No. 2, 305320, 2014.

11 This paper was supported by the Israel Science Foundation (grant no. 1168/16). I would like to thank the participants of the conference "Agency and Rationality" for a very helpful discussion. Special thanks are owed to Dalia Drai, David Horst, Hilla Jacobson, Sergio Tenenbaum and Ruth Weintraub, who patiently read many versions of this paper, and made crucial substantive comments. 

2017.

"Why Take Painkillers." Forthcoming in Nous,

BITTNER, R. "Is it Reasonable to Regret Things One Did?" The Journal of Philosophy, 89: 262-73, 1992.

BYRnE, A. 'Intentionalism Defended', Philosophical Review, 110: 199-239, 2001.

\& TYE, M. "Qualia ain't in the head." Nous 40(2): 241-255, 2006.

CUTTER, B. and M. TYE "Tracking Representationalism and the Painfulness of Pain”, Philosophical Issues, 21, 90109, 2011.

\& TYE, M. "Pains and Reasons: Why It Is Rational to Kill the Messenger." The Philosophical Quarterly 64(256): 423-433, 2014.

D'Arms, J. \& JACOBSON, D. “The Moralistic Fallacy: On the 'Appropriateness' of Emotion." Philosophy and Phenomenological Research, 61: 65-90, 2000.

Dretske, F. Naturalizing the Mind (MIT Press:Bradford Books, 1995).

HALl, R. J. “Are Pains Necessarily Unpleasant?”, Philosophy and Phenomenological Research 49: 643-659, 1989.

HeLm, B. "Felt Evaluations: A Theory of Pleasure and Pain." American Philosophical Quarterly, 39, 1, 13-30, 2002.

Hieronymi, P. "The Wrong Kind of Reason." Journal of Philosophy, 102: 437-457, 2005.

"The Use of Reasons in Thought (and the use of earmarks in arguments)," Ethics, 2012. 
Hume, D. In L. A. Selby-Bigge \& P. H. Nidditch (Eds.), A treatise of human nature $\left(2^{\text {nd }}\right.$ ed.). Oxford: Oxford University Press, 1739/1978..

JACOBSON, H. "Killing the Messenger: Representationalism and the Painfulness of Pain." The Philosophical Quarterly 63(252): 509-519, 2013.

JOLLIMORE, T. "Meaningful Happiness and Meaningful Suffering." Southern Journal of Philosophy, Vol. XLII: 333-347, 2004.

KLEIN, C. What the Body Commands: The Imperative Theory of Pain. MIT Press, 2015.

KORSGAARD, C. The sources of normativity. Cambridge: Cambridge University Press, 1996.

LitTLE, M. "Virtue as Knowledge: Objections from the Philosophy of Mind." Nous 31.1: 59-79, 1997.

MCDowell, J. "Projection and Truth in Ethics." Lindley Lecture 1987. University of Kansas. Reprinted in his Mind, Value and Reality. Cambridge, MA. Harvard University Press. 1998: 151-66, 1987. 1979.

NAgel, T. The Possibility of Altruism (Princeton University Press), 1970.

Nietzsche, F. The Gay Science. Ed. By B. Williams (Cambridge: Cambridge University Press), 2001.

NussBaum, M. Upheavals of Thought (Cambridge: Cambridge University Press), 2001.

PARFIT, D. 'Rationality and Reasons,' in Dan Egonsson et al. (eds.), Exploring Practical Philosophy (Burlington VT: Ashgate), 17-39, 2001. 
PILLER, C. "Normative Practical Reasoning," Proceedings of the Aristotelian Society 75, Supp (1), 195-216, 2001.

SARTRE, P. [1943] Being and Nothingness, Philosophy Library Inc, 1992 [1943].

SCANLON, T. What We Owe to Each Other, Cambridge MA: Harvard University Press, 1998.

SCHROEDER, M. "The Ubiquity of State-Given Reasons," Ethics 122: 457-488, 2012.

SPINOZA, B. Ethics. Translated by E. Curley (Penguin Classics), 2005.

STAMP, D. The authority of desire. Philosophical Review, 96, 335-381, 1987.

TAYLOR, G. Pride, Shame, and Guilt: Emotions of Selfassessment. New York: Oxford University Press, 1985.

TYE, M. Ten Problems of Consciousness: A representational theory of the phenomenal mind. Cambridge: MIT Press, 1995.

"Another Look at Representationalism about Pain." In Pain: New Essays on Its Nature and the Methodology of Its Study, edited by M. Aydede. Cambridge, Massachusetts: MIT Press, 2005.

Wallace, J. The View from Here. On Affirmation, Attachment, and the Limits of Regret (New York: Oxford University Press), 2013.

Wiggins, D. "A Sensible Subjectivism?" In his Needs, Values, Truth, 1998, 185-214. Oxford: Oxford University Press, 1987.

"Truth, Invention, and the Meaning of Life." Reprinted in his 1998: 87-138, 1976.

\section{(cc) $\mathrm{EY}$}

